\section{The ultimate breakdown protection}

Are you worried about what could happen if your Little Sister autoclave breaks down?

Make sure you keep your systems protected by choosing the Care\&Cover warranty from Eschmann - the fourth emergency service!

This high-quality warranty not only provides up to two scheduled service visits per year, but also includes verifiable CPD training for the whole team.

Furthermore, the warranty allows you to benefit from nationwide coverage and access to the Eschmann team of over 70 engineers - all of whom have been specifically trained to repair Eschmann products.

Keep your Little Sister safe by contacting Eschmann today. For more information on the highly effective and affordable range of decontamination equipment and products from Eschmann, visit www.eschmann.co.uk or call 01903753322.

\section{Would you like a free lunch?}

In just 30 minutes you and your team can discover the benefits of Ultaire AKP - a premium alternative for removable partial dentures that is biocompatible, lightweight and metal-free.

Simply contact Solvay Dental 360 and one of our representatives will contact you within 24 hours to arrange a Virtual Lunch and Learn. You will receive an Ultaire AKP Resource Kit and Solvay Dental 360 will even pay for your lunch!

To book a Solvay Dental 360 Professional Lunch and Learn or to find more information about Ultaire AKP and Dentivera milling discs, visit https://www.solvaydental360.com/ virtualmeeting/?lang=en_gb.

\section{A reason to smile}

Want to offer your patients an orthodontic appliance at the forefront of development? Choose Clarity ADVANCED ceramic brackets from 3M Oral Care.

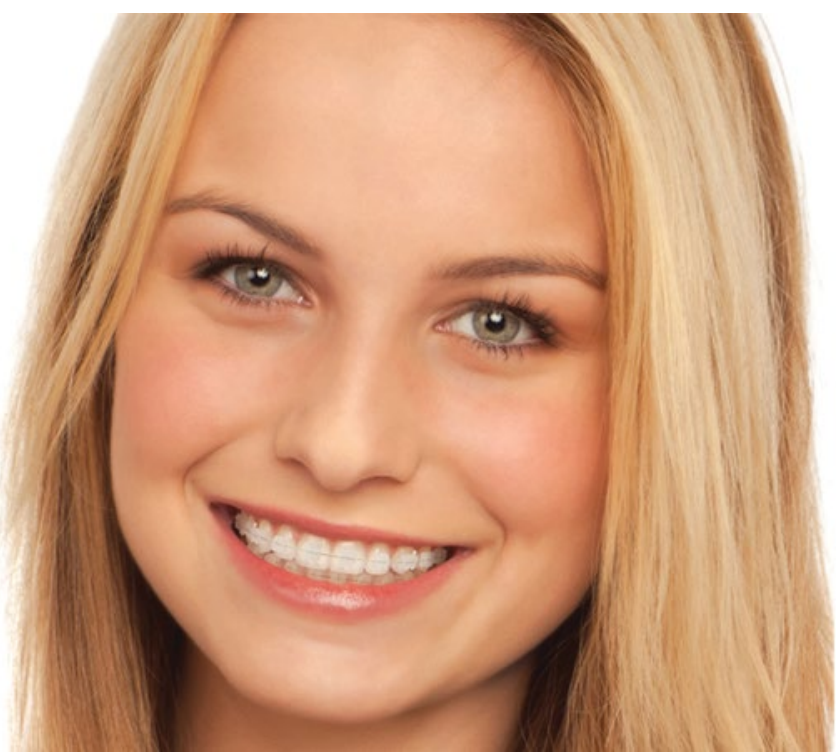

Designed for maximum versatility, the brackets offer ample under tie-wing space, granting flexible treatment and ligation options, including double ligation if necessary. Clarity Advanced ceramic brackets also feature bi-directional ball hooks that are designed to enhance positioning and patient comfort, meaning they both look and feel great - a real reason to smile!

Find out more by contacting the friendly team at $3 \mathrm{M}$ Oral Care today. For more information, call 08458734066 or visit http:// solutions.3m.co.uk/wps/portal/3M/en_GB/orthodontics_EU/Unitek/. $3 \mathrm{M}$ and Clarity are trademarks of the $3 \mathrm{M}$ Company.

\title{
What do you do with waste?
}

Dental practices generate many different types of waste. Whether it's amalgam removed from people's mouths, municipal waste in the waiting room or used aprons and gloves, all waste has to be disposed of properly.

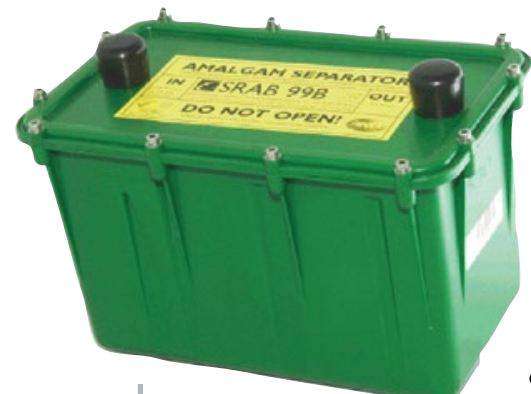

But how can you give staff the best chance of sorting waste effectively? Introduce them to the Colour Code Characters from Initial Medical. A fun personification of the Department of Health's colour coded guide for best practice waste disposal, these characters help make the different waste streams and disposal methods more memorable.
Find out more and request your free posters with the Colour Code Characters by contacting Initial Medical.

For further information visit www.initial.co.uk/medical or call 08708504045 .

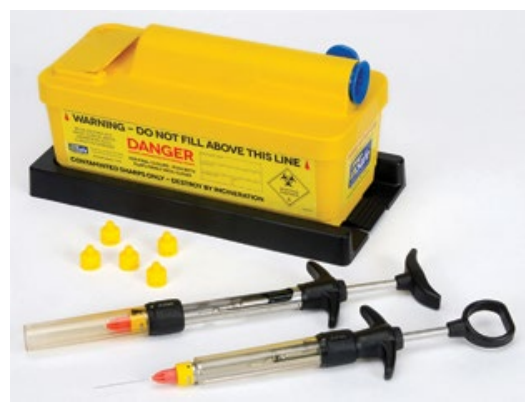

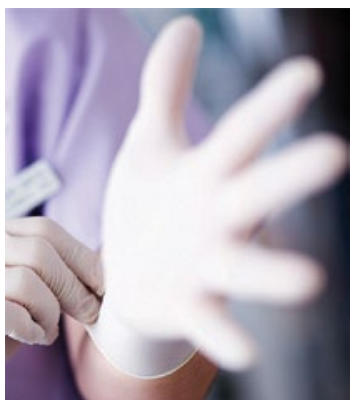

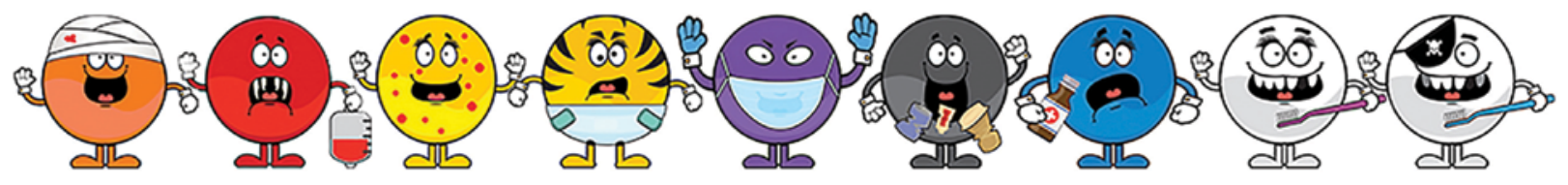

